\title{
Primary hyperparathyroidism: a retrospective study over 18 years in an oncology center
}

\author{
Ana C Martins*,1,2 (iD), Helder Simões ${ }^{1} \&$ Valeriano Leite ${ }^{1}$ \\ ${ }^{1}$ Endocrinology Department, Instituto Português de Oncologia de Lisboa Francisco Gentil, Lisbon, Portugal \\ ²Endocrinology Department, Centro Hospitalar Universitário Lisboa Central, Lisbon, Portugal \\ *Author for correspondence: ana.c.martins@chlc.min-saude.pt
}

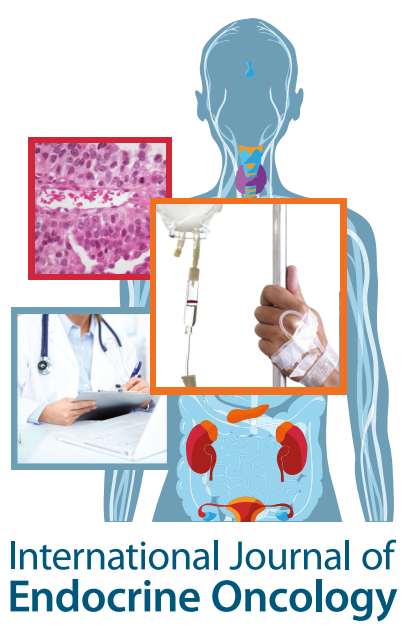

\begin{abstract}
Aim: To study primary hyperparathyroidism (pHPT) in an oncology center, including its possible association with malignancy and ionizing radiation. Methods: Retrospective analysis of 188 patients with sporadic pHPT treated with parathyroidectomy between 2000 and 2018 . We studied the etiology, clinical and biochemical features of pHPT, history of malignancies and exposure to radiotherapy. Results: pHPT was caused by parathyroid adenoma in $90.4 \%$, hyperplasia in $5.3 \%$ and carcinoma in $4.3 \%$. Cure and recurrence rates of pHPT were 99 and 4.3\%, respectively. Median follow-up time was 19 months. Prevalence of malignancies was $30 \%$, mostly thyroid and breast cancer. Radiotherapy of the head, neck or thorax $(8.5 \%)$ was not associated with worse hypercalcaemia or recurrence. Males had larger adenomas, higher calcium and parathyroid hormone $(p<0.01)$. Conclusion: Prevalence of parathyroid carcinoma and other malignancies was higher than reported in other studies. Ionizing radiation exposure was unrelated with pHPT severity. Men had more severe pHPT. High cure and low recurrence rates were achieved.
\end{abstract}

First draft submitted: 10 June 2019; Accepted for publication: 26 September 2019; Published online: 8 November 2019

Keywords: gender differences $\bullet$ ionizing radiation $\bullet$ malignancy $\bullet$ parathyroid carcinoma $\bullet$ primary hyperparathyroidism • thyroid carcinoma

Primary hyperparathyroidism (pHPT) is characterized by hypercalcemia, resulting from inappropriately high parathyroid hormone (PTH) secretion [1]. It has an incidence of 66 cases per 100,000 persons per year among women and 25 per 100,000 persons per year among men, with an estimated prevalence of $0.1 \%$ in the general population [2-5]. Most cases of pHPT are sporadic and generally caused by a parathyroid adenoma (85\%), while parathyroid hyperplasia occurs in $15 \%$ of cases and parathyroid carcinoma in $<1 \%[1,2]$. The only curative treatment is parathyroidectomy, with rates of cure $>95 \%$, when performed by experienced surgeons [1].

Physiopathology of pHPT comprises multiple mechanisms. In syndromic or hereditary pHPT, as in hyperparathyroidism jaw-tumor syndrome and multiple endocrine neoplasia types 1, 2A and 4, a single genetic mutation is responsible for the disease. In nonsyndromic pHPT, although the genetic basis is not yet fully understood, several molecular pathways involved in parathyroid tumorigenesis have been investigated [1,6-8]. Growth factors including VEGF, TGF $\beta$ and IGF-1 have been found to be increased in pHPT [1,7]. These proteins stimulate cell proliferation and differentiation, and are thought to be implicated in growth regulation of parathyroid tumors. Cyclins are regulators of the cell cycle and cyclin D1, encoded by the gene CCND1, promotes cell-cycle progression [1]. Overexpression of CCND1 has been found in 20-40\% of parathyroid adenomas and in parathyroid carcinomas [7]. Mutations of the $R B$ gene, an inhibitor of the cell-cycle progression, have also been observed in parathyroid carcinomas [7]. Moreover, sporadic parathyroid tumors may harbor somatic mutations in the $M E N 1$ gene [1]. In whole exome sequencing studies, PRUNE2 was found to be recurrently mutated on a germline and somatic manner in a subset of parathyroid carcinomas [8]. In the same study, the $A P O B E C$ mutational signature was found to be dominant in another subset of parathyroid carcinoma patients with high mutational burden and early age onset of disease [8].

Beyond genetic alterations, risk factors for pHPT include female sex and exposure to ionizing radiation [6,9-12]. Irradiation has been associated with pHPT especially in patients who received radiation treatment of the head and neck region in childhood $[9,10]$. In a prospective study of 2923 patients exposed to radiotherapy in childhood,

Future $\because$ Medicine 
the incidence of pHPT was 2.9-times greater than in the general population [9]. An increased risk of pHPT was also observed in Hiroshima (Japan) atomic bomb survivors and in workers at the Chernobyl Nuclear Power Plant (Pripyat, Ukraine) [13,14]. Radiation-associated hyperparathyroidism seems to occur after a long period of time after exposure to radiation [12].

Classical manifestations of pHPT are related to kidney and skeletal damage, including nephrolithiasis, nephrocalcinosis, decreased renal function, low bone mineral density, bone cysts and brown tumors. In developed countries, however, the clinical presentation of pHPT has changed over the years and is now, in most cases, diagnosed in asymptomatic patients [15-17].

Besides the classical presentation, pHPT has been linked to neurocognitive changes, cardiovascular dysfunction and malignancy [15,17-20]. In fact, an increased risk of cancer-related death in patients with pHPT has been reported [21,22] and pHPT has been associated with a number of malignancies, such as breast, colon, kidney, thyroid and skin cancer $[19,20,23-25]$. A possible antiapoptotic effect of parathyroid hormone could contribute to an increased risk of cancer; however, such risk seems to persist after parathyroidectomy, suggesting that common etiologic factors may exist for pHPT and some malignancies [24,25].

In this study, we retrospectively reviewed a series of patients with sporadic pHPT, who were treated with parathyroidectomy between 1 January 2000 and 30 June 2018. We studied associations between pHPT and malignancies, and tried to understand the role of previous exposure to ionizing radiation in PHPT and its manifestations.

\section{Materials \& methods}

A total of 196 parathyroidectomies performed between 1 January 2000 and 30 June 2018 were identified and clinical records, pathology reports, biochemical and imaging studies of the patients were reviewed. Based on this information, we excluded cases of tertiary hyperparathyroidism $(\mathrm{n}=3)$, familial primary hyperparathyroidism $(\mathrm{n}=4)$ and multiple endocrine neoplasia $(\mathrm{n}=1)$. All the patients with diagnosis of sporadic PHPT who had parathyroidectomy in the above-mentioned period were included in the study $(\mathrm{n}=188)$.

We have documented for each patient the concentrations of total serum calcium, phosphate, intact PTH, magnesium, calcifediol, creatinine and 24-h urine calcium and phosphate. Serum calcium, phosphate and PTH from the last follow-up appointment were also recorded. Serum intact PTH was determined using a third-generation PTH assay (PTH1-34 and 44-84). Information regarding the reason that led to diagnosis, symptoms attributable to $\mathrm{pHPT}$, history of previous fragility fractures, personal and family history of malignancies and previous exposure to ionizing radiation was obtained from the clinical records. Pathology reports from parathyroidectomies were reviewed for histological diagnosis, location and dimensions of parathyroid adenomas and carcinomas. Imaging studies were also reviewed for the presence of nephrolithiasis or calcinosis, bone mineral density, presence or absence of enlarged parathyroid glands and concordance of localization.

\section{The study was approved by the Institutional Ethics Committee}

Statistical analysis

Statistical analysis of the results was performed with Microsoft Excel ${ }^{\circledR}$ and IBM SPSS ${ }^{\circledR}$. Data are presented as means and standard deviations, or as medians and intervals, as appropriate. A one-sample Kolmogorov-Smirnov was performed to test for normality of quantitative variables. We used the Mann-Whitney test to compare differences and the Spearman coefficient for correlations between variables, considering data as statistically significant if $\mathrm{p}<0.05$.

\section{Results}

We studied 188 patients with sporadic pHPT, including 151 females (80\%) and 37 males (20\%). At diagnosis, mean age was $59 \pm 14.7$ years (median 61 years, range 14-93).

In most cases (59\%), pHPT was diagnosed through routine laboratory tests. Symptoms attributable to pHPT occurred in $23.4 \%$, with the most common being bone pain and fatigue (Table 1 ).

Table 2 shows the laboratory profile of patients at diagnosis.

Target organ lesions were present in 134 patients $(71.3 \%)$, the most common being nephrolithiasis, which was documented in $66.4 \%$. The prevalence of target organ lesions at diagnosis was significantly higher in the first years of the studied period (2000-2004) when compared with the last years (2014-2018) - 86.8 versus 51.4\%, respectively ( $\mathrm{p}<0.01)$. Table 3 shows the full frequency of target organ lesions. 
Table 1. Motive for diagnosis of primary hyperparathyroidism.

\begin{tabular}{|l}
\hline Motive for diagnosis \\
\hline Routine laboratory tests \\
\hline - Bone pain \\
\hline - Fatigue \\
\hline - Abdominal pain/vomiting \\
\hline - Dizziness \\
\hline - Renal colic \\
\hline - Mental confusion \\
\hline Nephrolithiasis \\
\hline Palpable nodule of the neck \\
\hline Osteoporosis \\
\hline Maxillary brown tumor \\
\hline Incidental in thyroidectomy \\
\hline
\end{tabular}

\begin{tabular}{l} 
Frequency (\%) \\
$111(59)$ \\
$44(23.4)$ \\
16 \\
12 \\
8 \\
4 \\
\hline 2 \\
2 \\
\hline $17(9)$ \\
\hline $8(4.3)$ \\
\hline $4(2.1)$ \\
\hline $2(1.1)$ \\
\hline $2(1.1)$ \\
\hline
\end{tabular}

Table 2. Initial laboratorial evaluation in patients with primary hyperparathyroidism.

\begin{tabular}{|c|c|c|}
\hline Biochemical features & Median (interval) & Normal range \\
\hline Total calcium $(\mathrm{mg} / \mathrm{dl})-\mathrm{n}=187$ & $11.5(9.2-20)$ & $8.4-10.2$ \\
\hline Phosphate $(\mathrm{mg} / \mathrm{dl})-\mathrm{n}=183$ & $2.5(0.9-4.1)$ & $2.3-4.7$ \\
\hline Magnesium $(\mathrm{mg} / \mathrm{dl})-\mathrm{n}=116$ & $2.1(1.1-2.7)$ & $1.6-2.6$ \\
\hline Serum intact PTH $^{\dagger}(\mathrm{pg} / \mathrm{ml})-\mathrm{n}=187$ & $186(53.1-3150)$ & $12-65$ \\
\hline $25(\mathrm{OH})$ vitamin $D^{\ddagger}(\mathrm{ng} / \mathrm{ml})-\mathrm{n}=82$ & $17.5(8-79)$ & $9-45$ \\
\hline 24-h urine calcium $(\mathrm{mg} / 24 \mathrm{~h})-\mathrm{n}=83$ & $313(59-994)$ & $100-300$ \\
\hline 24-h urine phosphate $(\mathrm{mg} / 24 \mathrm{~h})-\mathrm{n}=62$ & $794(138-2293)$ & $400-1300$ \\
\hline
\end{tabular}

\begin{tabular}{|c|c|c|c|c|}
\hline \multirow[t]{2}{*}{ Target organ lesion } & \multicolumn{3}{|c|}{ Frequency (\%) } & \multirow[t]{2}{*}{ p-value } \\
\hline & Total & $\begin{array}{l}\text { pHPT diagnosed } \\
2000-2004\end{array}$ & $\begin{array}{l}\text { pHPT diagnosed } \\
2014-2018\end{array}$ & \\
\hline Nephrolithiasis/nephrocalcinosis & $97(66.4), n=146$ & $24(66.7), n=36$ & $11(40.7), n=27$ & 0.04 \\
\hline Renal dysfunction $^{\dagger}$ & $29(15.5), n=187$ & $8(21), n=38$ & $7(18.9), n=37$ & 0.82 \\
\hline Osteoporosis $\ddagger$ & $48(58.5), n=82$ & $16(61.5), n=26$ & $7(31.8), n=22$ & 0.04 \\
\hline Fragility fracture (reported) & $15(8), n=188$ & $5(13.2), n=38$ & $2(5.4), n=37$ & 0.25 \\
\hline No. of patients with any target organ lesion & $134(71.3), \mathrm{n}=188$ & $33(86.8), n=38$ & $19(51.4), n=37$ & 0.001 \\
\hline $\begin{array}{l}\text { †Serum creatinine }>1.11 \mathrm{mg} / \mathrm{dl} . \\
\text { †Documented in osteodensitometry } \\
\text { pHPT: Primary hyperparathyroidism. }\end{array}$ & & & & \\
\hline
\end{tabular}

Each patient had an average of two imaging studies for localization of enlarged parathyroid glands. Neck ultrasound and $99 \mathrm{~m} \mathrm{Tc}$-Sestamibi parathyroid scintigraphy were the most commonly used imaging methods, in 88.3 and $75 \%$, respectively, whereas neck CT scan was performed in $21.8 \%$ and MRI in $17.6 \%$. In $86.7 \%$ of the cases the location of abnormal parathyroid glands, as seen in the imaging studies, was concordant with the surgical report.

Time between diagnosis and surgery was $<1$ year for $75.5 \%$, between 1 and 2 years for $14.9 \%$ and over 2 years for $9.6 \%$. A parathyroid adenoma was identified in 170 cases $(90.4 \%)$, parathyroid hyperplasia in 10 (5.3\%) and carcinoma in $8(4.3 \%)$. The largest tumor diameter was $21.4 \pm 9 \mathrm{~mm}$ in parathyroid adenomas and $32.1 \pm 20 \mathrm{~mm}$ in carcinomas. Most adenomas were located at the right inferior (41.2\%) and left inferior (32.9\%) parathyroid glands. There were two ectopic adenomas (retroesophageal and mediastinal). 
Table 4. Malignancies in patients with primary hyperparathyroidism.

\begin{tabular}{|l|l|}
\hline Malignancies & Frequency (\%) \\
\hline Papillary thyroid carcinoma & $26(13.8)$ \\
\hline Bematological malignancies: & $14(7.4)$ \\
\hline - Non-Hodgkin's lymphoma & $7(3.7)$ \\
\hline - Chronic lymphocytic leukemia & 3 \\
\hline - Acute lymphoblastic leukemia & 2 \\
\hline - Multiple myeloma & 1 \\
\hline Head and neck basal cell carcinoma & 1 \\
\hline Prostate adenocarcinoma & $4(2.1)$ \\
\hline Other & $3(1.6)$ \\
\hline
\end{tabular}

The cure rate was $99 \%(186 / 188)$. Median follow-up time was 19 months (0-214 months). Recurrence of pHPT occurred in eight patients (4.3\%), between 1 and 10 years after parathyroidectomy (median 6.5 years).

pHPT \& malignancy

Prevalence of malignancies was $30.3 \%$, the most frequent being papillary thyroid carcinoma (13.8\%), followed by breast cancer (7.4\%). See Table 4 for summary of malignancies. Seven patients had two malignancies and one had four malignancies.

Among 26 patients with papillary thyroid carcinoma, only four had been treated with radioiodine before the diagnosis of pHPT.

Known family history of malignancy was present in 15 patients (8\%), in at least one first or second-degree relative. The most frequently reported malignancies were from the GI tract (seven cases), breast (three cases) and kidney (three cases). The age at diagnosis of pHPT was significantly lower in patients with a family history of malignancy (median age 53 vs 62 years, $\mathrm{p}<0.05$ ); however, serum calcium, adenoma size and recurrence rate were similar between the two groups.

\section{pHPT \& radiotherapy exposure}

Sixteen patients $(8.5 \%)$ had been exposed to radiotherapy of the head, neck or thorax, between 1 and 19 years before the diagnosis of pHPT (median 5 years). Among these, ten patients had radiotherapy for breast carcinoma, three for head and neck cancer, two for non-Hodgkin's lymphoma and one for acute lymphoblastic leukemia (CNS-directed radiotherapy).

There were no significant differences in serum calcium, histological diagnosis, adenoma size or recurrence rate between patients exposed and nonexposed to ionizing radiation (Table 5).

\section{Gender differences in PHPT}

In this series, 151 patients were females, with a female-to-male ratio of approximately 4:1. Women, compared with men, were more frequently diagnosed through routine laboratory tests, although this was also the main route of diagnosis in men. Male patients had higher median serum concentrations of total calcium and PTH and larger adenomas. Nevertheless, the rates of target organ lesions, such as nephrolithiasis and osteoporosis, and the recurrence rate of pHPT, were not significantly different between males and females. Table 6 shows full breakdown of gender differences.

\section{Discussion}

We describe a large series of patients with pHPT and their clinical evolution over time. Consistent with other series $[17,26]$, we have obtained high cure $(99 \%)$ and low recurrence $(4.3 \%)$ rates. This study shows recurrences occurred with a median of 6.5 years after parathyroidectomy, whereas other studies have reported recurrence rates between 0 and 5\%, but most have shorter follow-up times [26,27].

In the majority of cases, pHPT was caused by a parathyroid adenoma. However, compared with other series [2830], there was a relatively higher prevalence of parathyroid carcinoma (4.3\%) and a lower than expected prevalence of hyperplasia (5.3\%). In the first case, this might be due to the study taking place in an oncology center and, in 
Table 5. Features of primary hyperparathyroidism in patients previously exposed and not exposed do radiotherapy of the head, neck or thorax.

\begin{tabular}{|c|c|c|c|}
\hline Features of primary hyperparathyroidism & Patients exposed to RT & Patients not exposed to RT & p-value \\
\hline Total serum calcium (mg/dl) - median (interval) & $11.6(10.5-12.5)$ & $11.5(9.2-20)$ & 0.52 \\
\hline \multicolumn{4}{|l|}{ Histological diagnosis: } \\
\hline - Parathyroid hyperplasia - n (\%) & $1(6)$ & $9(5.2)$ & \\
\hline - Parathyroid carcinoma - n (\%) & 0 & $8(4.7)$ & \\
\hline Age at diagnosis (years) - median (interval) & $61.2(17-79)$ & $60.6(14-93)$ & 0.59 \\
\hline \multicolumn{4}{|l|}{ Target organ lesions: } \\
\hline - Nephrolithiasis/nephrocalcinosis - n (\%) & $7(58), n=12$ & $90(67), n=134$ & 0.54 \\
\hline - Renal dysfunction ${ }^{\dagger}-\mathrm{n}(\%)$ & $1(7), n=15$ & $28(16), n=172$ & 0.33 \\
\hline - Osteoporosis ${ }^{\ddagger}$ - n (\%) & $4(67), n=6$ & $44(58), n=76$ & 0.68 \\
\hline - Fragility fracture (reported) - n (\%) & $2(13), n=16$ & $13(8), n=172$ & 0.49 \\
\hline - Any target organ lesion - n (\%) & $9(56), n=16$ & $125(73), n=172$ & 0.17 \\
\hline Cure after parathyroidectomy - n (\%) & $16(100)$ & $170(99)$ & 0.67 \\
\hline Recurrence - n (\%) & $1(6)$ & $7(4)$ & 0.68 \\
\hline $\begin{array}{l}\dagger \text { Serum creatinine }>1.11 \mathrm{mg} / \mathrm{dl} \text {. } \\
\text { ‡Documented in osteodensitometry. } \\
\text { RT: Radiotherapy. }\end{array}$ & & & \\
\hline
\end{tabular}

Table 6. Gender differences in primary hyperparathyroidism.

Features of primary hyperparathyroidism

Males Females p-value

Total serum calcium (mg/dl); median (interval)

$12.5(10.3-20)$

$11.4(9.2-16.5)$

$<0.001$

Total serum phosphate (mg/dl); median (interval)

$2.25(0.9-3.9)$

$2.5(1.2-4.1)$

0.005

Serum intact $\mathrm{PTH}^{\dagger}(\mathrm{pg} / \mathrm{ml})$; median (interval)

255 (70-2091)

$164(53-3150)$

0.001

25(OH)vitamin $D^{\ddagger}(\mathrm{ng} / \mathrm{ml})$; median (interval)

22 (8-45)

16 (8-79)

0.46

24-h urine calcium (mg/24h); median (interval)

545 (63-994)

302 (59-883)

0.02

Largest diameter of parathyroid adenoma $(\mathrm{mm})$; median (interval)

25 (10-70)

$20(6-55)$

0.003

Age at diagnosis (years); median (interval)

58 (14-93)

$61(15-87)$

0.12

Motive for diagnosis:

- Routine laboratory tests; $\mathrm{n}(\%)$

$16(43)$

95 (63)

0.03

- Symptoms; n (\%)

$11(30)$

33 (22)

- Nephrolithiasis; n (\%)

- Other; n (\%)

5 (14)

$12(8)$

0.31

Nephrolithiasis/nephrocalcinosis; $\mathrm{n}(\%)$

5 (14)

$11(7)$

0.29

Renal dysfunction ${ }^{\S}$; (\%)

20 (65)

77 (67)

0.23

Osteoporosis"; n (\%)

8 (22)

21 (14)

0.8

Fragility fracture (reported); $\mathrm{n}(\%)$

$10(59)$

38 (59)

0.25

Any target organ lesion; $\mathrm{n}(\%)$

Cure after parathyroidectomy; n (\%)

3 (8)

$12(8)$

0.98

$29(78)$

105 (70)

0.97

Recurrence; $\mathrm{n}$ (\%)

37 (100)

149 (99)

0.29

0

8 (5)

$\dagger$ Parathyroid hormone.

$\ddagger$ Calcifediol.

$\S$ Serum creatinine $>1.11 \mathrm{mg} / \mathrm{dl}$.

\#Documented in osteodensitometry

the second, because familial cases of $\mathrm{pHPT}$, in which parathyroid hyperplasia is a frequent cause of $\mathrm{pHPT}$, were excluded.

The overall prevalence of target organ lesions was considerable, especially for nephrolithiasis, reaching $66.7 \%$ in the first years of the studied period (2000-2004) and declining to $40.7 \%$ in the latest (2014-2018). Similar rates 
have been reported in other series $[15,31,32]$. At present, renal stones may be found in $25-55 \%$ of systematically screened patients [31].

Imaging studies, mostly ultrasound and parathyroid scintigraphy, were able to correctly locate the abnormal parathyroid glands in almost $90 \%$ cases. In a recent meta-analysis, sensitivity/specificity was $80 / 77 \%$ for ultrasound and $84 / 87 \%$ for scintigraphy [33]. Moreover, when used in combination, the two methods perform better than each does individually [34]. Parathyroid adenoma size is also an important factor when evaluating the accuracy of imaging studies; in our study, the largest diameter of adenoma was relatively high $(21.4 \pm 9 \mathrm{~mm})$ and this was even higher in carcinomas $(32.1 \pm 20 \mathrm{~mm})$.

Several types of malignancies have been described in association with pHPT [21]. In our study, the prevalence of malignancies (30.3\%) was higher than reported in literature, which varies from 12 to $18 \%$ [19-21]. In a Swedish cohort including 9782 cases of surgically treated PHPT, an increased risk of kidney, intestinal and squamous cell skin cancer was observed in both genders, as well as of breast cancer in women [20]. Another study, conducted in Denmark, found an increased incidence of hematopoietic malignancies, particularly multiple myeloma, among 2425 patients with $\mathrm{pHPT}$ [19]. In our series, papillary thyroid carcinoma and breast cancer were the most frequently observed malignancies, with prevalence of 13.8 and $7.4 \%$, respectively.

The association between $\mathrm{pHPT}$ and breast cancer has been previously reported in case series $[35,36]$ and $\mathrm{pHPT}$ has been related to the risk of breast cancer in a cohort study in Sweden [37]. Moreover, Palmieri et al. reported breast cancer prevalence of $12.2 \%$ in pHPT patients [25]. In our series, most patients with breast carcinoma had been previously treated with radiotherapy and, although this is a known risk factor for $\mathrm{pHPT}$, it probably does not solely account for the relatively high frequency of this malignancy in our study population. Notably, radiotherapy exposure did not seem to affect recurrence rates of pHPT, nor its severity.

Thyroid disease is a common finding in patients with PHPT [38,39]. The estimated incidence of papillary thyroid carcinoma in patients with pHPT is $2-4.3 \%[2,39]$. In a retrospective study, the prevalence of thyroid cancer in patients with $\mathrm{pHPT}$ who had parathyroidectomy and thyroid surgery was $12.9 \%$, similar to that found in our series [40]. The simultaneous presence of these two disorders, if not recognized, may complicate patient management, particularly surgical approach; hence, routine neck imaging to evaluate concurrent thyroid nodules in patients with pHPT has been proposed [39]. While the best approach is not yet defined in these cases, tailored management based on multidisciplinary team discussion should be warranted.

In this study, we have also found interesting differences in pHPT between males and females. Similar findings were previously reported in other studies, although not consistently [41,42]. Even though it is recognized that pHPT is more common in women, the 4:1 female-to-male ratio in our series is slightly higher than previously reported $[41,43,44]$. The causes for the gender difference in the incidence of pHPT are still not well known but may result, at least in part, from women's tendency to seek medical attention more often than men [45]. In fact, we have found that women were more frequently diagnosed with pHPT through routine laboratory tests than men. Interestingly, in an autopsy study [46], parathyroid adenomas and hyperplasia were found in approximately equal numbers of male and female subjects. In agreement with the observations by Mazeh et al. [41], in our series of male patients we observed higher concentrations of serum calcium, PTH and urinary calcium, as well as larger parathyroid adenomas than in females. However, this does not seem to have a negative effect on target organs, including renal stones, or on recurrence rates.

There are a few limitations to our study. The retrospective nature of the study and the relatively small number of patients from a single center may give rise to selection bias and some findings cannot be generalized to a wider population with pHPT. Moreover, as a significant amount of data was obtained from clinical records, some information was unavailable and therefore could not be included in the study.

\section{Conclusion}

This study describes a population with surgically treated pHPT in a cancer center. Cure and recurrence rates were, however, similar to those reported in nononcological hospitals. The gender differences in biochemical presentation of $\mathrm{pHPT}$ found in our series, and previously described in some but not all studies, are an interesting but still unexplained finding. The higher prevalence of associated malignancies in our series compared with other publications, particularly papillary thyroid carcinoma and breast carcinoma, may provide some insight into the relation between $\mathrm{pHPT}$ and these malignancies and would be worth investigating in larger series. 


\section{Summary points}

- The connections between primary hyperparathyroidism and malignancy, for which common etiologic factors may exist, are still not completely understood.

- Our findings support the association between primary hyperparathyroidism and breast carcinoma, observed in previous studies.

- Radiotherapy exposure does not seem to influence the severity or the recurrence of primary hyperparathyroidism.

- Thyroid disease, particularly, papillary thyroid carcinoma, is frequently associated with primary hyperparathyroidism, which has important clinical implications.

- Gender differences in the presentation of primary hyperparathyroidism may exist, but do not seem to result in different outcomes.

Financial \& competing interests disclosure

The authors have no relevant affiliations or financial involvement with any organization or entity with a financial interest in or financial conflict with the subject matter or materials discussed in the manuscript. This includes employment, consultancies, honoraria, stock ownership or options, expert testimony, grants or patents received or pending, or royalties.

No writing assistance was utilized in the production of this manuscript.

\section{Ethical conduct of research}

The authors state that they have obtained appropriate institutional review board approval or have followed the principles outlined in the Declaration of Helsinki for all human or animal experimental investigations. In addition, for investigations involving human subjects, informed consent has been obtained from the participants involved.

\section{Open access}

This work is licensed under the Attribution-NonCommercial-NoDerivatives 4.0 Unported License. To view a copy of this license, visit http://creativecommons.org/licenses/by-nc-nd/4.0/

\section{References}

Papers of special note have been highlighted as: $\bullet$ of interest; $\bullet \bullet$ of considerable interest

1. Mizamtsidi M, Nastos C, Mastorakos G et al. Diagnosis, management, histology and genetics of sporadic primary hyperparathyroidism: old knowledge with new tricks. Endocr. Connect. 7(2), R56-R68 (2018).

- Comprehensive review of sporadic primary hyperparathyroidism.

2. Beebeejaun M, Chinnasamy E, Wilson P, Sharma A, Beharry N, Bano G. Papillary carcinoma of the thyroid in patients with primary hyperparathyroidism: is there a link? Med. Hypotheses 103, 100-104 (2017).

- Insight into the possible basis of the association between primary hyperparathyroidism and papillary thyroid carcinoma.

3. Adami S, Marcocci C, Gatti D. Epidemiology of primary hyperparathyroidism in Europe. J. Bone Miner. Res. 17, N18-23 (2002).

4. Yeh MW, Ituarte PH, Zhou HC et al. Incidence and prevalence of primary hyperparathyroidism in a racially mixed population. J. Clin. Endocrinol. Metab. 98(3), 1122-1129 (2013).

5. Clarke BL. Epidemiology of primary hyperparathyroidism. J. Clin. Densitom. 16(1), 8-13 (2013).

6. Wilhelm SM, Wang TS, Ruan DT et al. The American Association of Endocrine Surgeons guidelines for definitive management of primary hyperparathyroidism. JAMA Surg. 151(10), 959-968 (2016).

7. Segiet OA, Deska M, Michalski M, Gawrychowski J, Wojnicz R. Molecular profiling in primary hyperparathyroidism. Head Neck 37(2), 299-307 (2015).

8. Yu W, McPherson JR, Stevenson M et al. Whole-exome sequencing studies of parathyroid carcinomas reveal novel PRUNE2 mutations, distinctive mutational spectra related to APOBEC-catalyzed DNA mutagenesis and mutational enrichment in kinases associated with cell migration and invasion. J. Clin. Endocrinol. Metab. 100(2), E360-E364 (2015).

9. Cohen J, Gierlowski TC, Schneider AB. A prospective study of hyperparathyroidism in individuals exposed to radiation in childhood. JAMA 264(5), 581-584 (1990).

10. Mcmullen T, Bodie G, Gill A et al. Hyperparathyroidism after irradiation for childhood malignancy. Int. J. Radiat. Oncol. Biol. Phys. 73(4), 1164-1168 (2009).

11. Mihailescu D, Shore-Freedman E, Mukani S, Lubin J, Ron E, Schneider AB. Multiple neoplasms in an irradiated cohort: pattern of occurrence and relationship to thyroid cancer outcome. J. Clin. Endocrinol. Metab. 87(7), 3236-3241 (2002).

12. Stephen AE, Chen KT, Milas M, Siperstein AE. The coming of age of radiation-induced hyperparathyroidism: evolving patterns of thyroid and parathyroid disease after head and neck irradiation. Surgery 136(6), 1143-1153 (2004). 
13. Fujiwara S, Sposto R, Ezaki H et al. Hyperparathyroidism among atomic bomb survivors in Hiroshima. Radiat. Res. 130, 372-378 (1992).

14. Boehm BO, Rosinger S, Belyi D, Dietrich JW. The parathyroid as a target for radiation damage. N. Engl. J. Med. 365(7), 676-678 (2011).

15. Khan AA, Hanley DA, Rizzoli R et al. Primary hyperparathyroidism: review and recommendations on evaluation, diagnosis, and management. A Canadian and international consensus. Osteoporos. Int. 28(1), 1-19 (2017).

16. Bilezikian JP, Brandi ML, Eastell R et al. Guidelines for the management of asymptomatic primary hyperparathyroidism: summary statement from the Fourth International Workshop. J. Clin. Endocrinol. Metab. 99(10), 3561-3569 (2014).

17. Pappachan JM, Elnaggar MN, Sodi R, Jbeili K, Smith PR, Lahart IM. Primary hyperparathyroidism: findings from the retrospective evaluation of cases over a 6-year period from a regional UK centre. Endocrine 62(1), 174-181 (2018).

18. Wermers RA, Khosla S, Atkinson EJ et al. Survival after the diagnosis of hyperparathyroidism: a population-based study. Am. J. Med. 104, 115-122 (1998).

19. Pickard A, Gridley G, Mellemkjæ L et al. Hyperparathyroidism and subsequent cancer risk in Denmark. Cancer 95(8), 1611-1617 (2002).

20. Nilsson IL, Zedenius J, Yin L, Ekbom A. The association between primary hyperparathyroidism and malignancy: nationwide cohort analysis on cancer incidence after parathyroidectomy. Endocr. Relat. Cancer 14(1), 135-140 (2007).

-• Insight into malignancies associated with primary hyperparathyroidism in a large population with long-term follow-up.

21. Goswami S, Ghosh S. Hyperparathyroidism: cancer and mortality. Indian J. Endocrinol. Metab. 16(Suppl. 2), S217-S220 (2012).

22. Hedback G, Tisell LE, Bengtsson BA, Hedman I, Oden A. Premature death in patients operated on for primary hyperperathyroidism. World J. Surg. 14, 829-836 (1990).

23. Strodel WE, Thompson NW, Eckhauser FE, Knol JA. Malignancy and concomitant primary hyperparathyroidism. J. Surg. Oncol. 37(1), 10-12 (1988).

24. Palmér M, Adami HO, Krusemo UB, Ljunghall S. Increased risk of malignant diseases after surgery for primary hyperparathyroidism - a nationwide cohort study. Am. J. Epidemiol. 127, 1031-1040 (1988).

-• First large cohort establishing an increased risk of malignancy in patients with primary hyperparathyroidism.

25. Palmieri S, Roggero L, Cairoli E et al. Occurrence of malignant neoplasia in patients with primary hyperparathyroidism. Eur. J. Intern. Med. 43, 77-82 (2017).

26. Ishii H, Mihai R, Watkinson JC, Kim DS. Systematic review of cure and recurrence rates following minimally invasive parathyroidectomy. BJS Open 2(6), 364-370 (2018).

27. Hedbäck G, Odén A. Recurrence of hyperparathyroidism; a long-term follow-up after surgery for primary hyperparathyroidism. Eur. J. Endocrinol. 148(4), 413-421 (2003).

28. Hakaim AG, Esselstyn CBJ. Parathyroid carcinoma: 50-year experience at The Cleveland Clinic Foundation. Cleve. Clin. J. Med. 60(4), 331-335 (1993).

29. Kebebew E, Clark OH. Parathyroid adenoma, hyperplasia, and carcinoma: localization, technical details of primary neck exploration, and treatment of hypercalcemic crisis. Surg. Oncol. Clin. N. Am. 7(4), 721-748 (1998).

30. Fraker DL, Harsono H, Lewis R. Minimally invasive parathyroidectomy: benefits and requirements of localization, diagnosis, and intraoperative PTH monitoring. long-term results. World J. Surg. 33(11), 2256-2265 (2009).

31. Cipriani C, Biamonte F, Costa AG et al. Prevalence of kidney stones and vertebral fractures in primary hyperparathyroidism using imaging technology. J. Clin. Endocrinol. Metab. 100(4), 1309-1315 (2015).

32. Silverberg SJ, Shane E, Jacobs TP et al. Nephrolithiasis and bone involvement in primary hyperparathyroidism. Am. J. Med. 89, 327-334 (1990).

33. Nafisi Moghadam R, Amlelshahbaz AP, Namiranian N et al. Comparative diagnostic performance of ultrasonography and

${ }^{99 \mathrm{~m}} \mathrm{Tc}$-sestamibi scintigraphy for parathyroid adenoma in primary hyperparathyroidism; systematic review and meta-analysis. Asian Pac. J. Cancer Prev. 18(12), 3195-3200 (2017).

34. Scattergood S, Marsden M, Kyrimi E, Ishii H, Doddi S, Sinha P. Combined ultrasound and sestamibi scintigraphy provides accurate preoperative localisation for patients with primary hyperparathyroidism. Ann. R. Coll. Surg. Engl. 101(2), 97-102 (2019).

35. Fierabracci P, Pinchera A, Miccoli P et al. Increased prevalence of primary hyperparathyroidism in treated breast cancer. J. Endocrinol. Invest. 24(5), 315-320 (2001).

36. Lee $\mathrm{SH}$, Kim BH, Bae MJ et al. Concurrence of primary hyperparathyroidism and metastatic breast carcinoma affected a parathyroid gland. J. Clin. Endocrinol. Metab. 98(8), 3127-3130 (2013).

37. Michels KB, Xue F, Brandt L, Ekbom A. Hyperparathyroidism and subsequent incidence of breast cancer. Int. J. Cancer 110(3), 449-451 (2004).

38. Wright MC, Jensen $\mathrm{K}$, Mohamed $\mathrm{H}$ et al. Concomitant thyroid disease and primary hyperparathyroidism in patients undergoing parathyroidectomy or thyroidectomy. Gland Surg. 6(4), 368-374 (2017). 
39. Spanheimer PM, Weigel RJ. Management of patients with primary hyperparathyroidism and concurrent thyroid disease: an evolving field. Ann. Surg. Oncol. 19(5), 1428-1429 (2012).

40. Simsek B, Guldogan CE, Ozden S, Saylam B, Karabeyoglu SM, Tez M. Concomitant thyroid cancer in patients with primary hyperparathyroidism in an endemic goitre region. Ann. Ital. Chir. 88, 15-19 (2017).

41. Mazeh H, Sippel RS, Chen H. The role of gender in primary hyperparathyroidism: same disease, different presentation. Ann. Surg. Oncol. 19(9), 2958-2962 (2012).

- Findings regarding gender differences in the presentation of primary hyperparathyroidism.

42. Castellano E, Attanasio R, Boriano A et al. Sex difference in the clinical presentation of primary hyperparathyroidism: influence of menopausal status. J. Clin. Endocrinol. Metab. 102(11), 4148-4152 (2017).

43. Richert L, Trombetti A, Herrmann FR et al. Age and gender distribution of primary hyperparathyroidism and incidence of surgical treatment in a European country with a particularly high life expectancy. Swiss Med. Wkly 139(27-28), 400-404 (2009).

44. Miller BS, Dimick J, Wainess R, Burney RE. Age- and sex-related incidence of surgically treated primary hyperparathyroidism. World J. Surg. 32(5), 795-799 (2008).

45. Wang Y, Hunt K, Nazareth I, Freemantle N, Petersen I. Do men consult less than women? An analysis of routinely collected UK general practice data. BMJ Open 3(8), e003320 (2013).

46. Akerström G, Rudberg C, Grimelius L et al. Histologic parathyroid abnormalities in an autopsy series. Hum. Pathol. 17(5), 520-527 (1986). 